Artigos/Articles

\title{
O pós-ápice da migração haitiana no país em notícia recortada em portal de notícias: algumas notas sobre escolhas epistemológicas
}

The post-climax of the Haitian migration in the country on a news report: some notes on epistemological choices

Marilda C. Cavalcanti ${ }^{1,2}$

\section{RESUMO}

Tendo como pano de fundo cenários de diversidade e multilinguismo ao longo de minha trajetória de pesquisa, focalizo, neste artigo, a migração haitiana no Brasil, migração essa que tomo como epítome do movimento acelerado de mudança na paisagem espaço temporal (e linguísticocomunicativa)no país.

Palavras-chave: minorias; migração haitiana; narrativas da mídia; ideologias.

\section{ABSTRACT}

Having as background research settings of multilingualism and diversity focused in my academic path, I highlight, in this article, the Hatian migration in Brazil. I take this migration as an epitome of the accelerated movement of change in the spacetime (and linguistic/communicative) landscape in the country.

Keywords: minorities; Hatian migration; media narratives; ideologies.

1. Universidade Estadual de Campinas. Campinas, São Paulo - Brasil. https://orcid.org/ 0000-0002-2381-108X. E-mail: marilda.cavalcanti@gmail.com

2. Pesquisadora CNPq. 


\section{Introdução}

Neste dossiê que homenageia John Schmitz, meu orientador de mestrado e, mais tarde, meu colega no Departamento de Linguística Aplicada (DLA)/Unicamp, minha contribuição se propõe a retomar um tema muito presente em nossas conversas no DLA, a saber, epistemologia no fazer pesquisa, aqui iluminado por estudo, ora em desenvolvimento, sobre a migração recente no Brasil, tendo como pano de fundo cenários anteriores da trajetória acadêmica.

O foco do artigo está, portanto, nas escolhas epistemológicas que permearam/vêm permeando minha pesquisa em alguns cenários vistos como marginais no Brasil pela sociedade e, muitas vezes, negligenciados como locus de investigação. Esses cenários, de alguma forma envolvem multilinguismos, ou seja, uma visão de multilinguismo complexo. Para Pietikainen; Kelly Holmes (2013:6), “[a] globalização contemporânea... tem impacto sobre o tipo de multilinguismo que é percebido como 'central' (isto é, normal, desejável e valorizado) e o que é considerado 'periférico' (isto é, marginal, desvalorizado e inútil)" " ${ }^{3}$. No caso da pesquisa desenvolvida (e da pesquisa orientada), o multilinguismo está relacionado com línguas/grupos minoritários e/ou naturalizados como minoritários (minoritarizados, Cf. Cavalcanti, 1999, 2006). Parto do pressuposto que nesses cenários aparecem de forma implícita ou explícita ideologias hegemônicas de língua(gem) relacionadas à política/cidadania/diversidade/marginalidade/racialização.

Tendo como objetivo mostrar como a 'mídia'4, focalizada aqui em um portal de notícias de jornal de circulação nacional, narra o momento pós-ápice da migração haitiana, o artigo está organizado em 3 partes, além da introdução e das considerações finais, mas transitórias, a saber: (1) multilinguismos e diversidades; (2) da pesquisa etnográfica ao olhar etnográfico sobre notícias de jornal; (3) o pós-ápice da migração haitiana: um recorte na aceleração da mobilidade contemporânea.

3. No original: "Contemporary globalization ... impacts on what kind of multilingualism is perceived as 'central' (i.e. normal, desirable, and valuable) and what is considered 'peripheral'(i.e. marginal, devalued and useless."

4. Utiliza-se 'mídia' aqui com conhecimento do debate existente sobre o uso do termo de forma genérica (Cf. Androutpoulous, 2014: 525). 


\title{
Multilinguismos e diversidades: foco nas margens
}

\author{
"Estar na margem é ser parte do todo, mas fora do \\ corpo principal." ${ }^{5}$ (bell hooks, Prefácio, 1984) \\ "A promessa de diversidade poderia... ser descrita \\ como um problema: o sinal de inclusão faz com que \\ os sinais de exclusão desapareçam." " (Sara Ahmed, \\ 2012: 65)
}

No fazer Linguística Aplicada ${ }^{7}$ (Cavalcanti, 2006), tanto individualmente como em conjunto com o grupo de pesquisa, as escolhas epistemológicas realizadas perpassa(v)am a metodologia e a teoria, uma não podendo prescindir da outra (Cf. Cavalcanti, 2006). Essas escolhas estavam diretamente relacionadas ao cenário de minorias e diversidades que elegi como focal a partir de 1990, quando comecei a investigar etnograficamente um curso de formação de professores no cenário indígena acreano. A pesquisa nesse curso, combinada à realização de docência voluntária, se estendeu por mais de dez anos. Esse cenário inicial foi ampliado, no grupo de pesquisa, para incluir outros cenários de diversidade que foram/eram trazidos por orientandos, cenários esses em que os atores eram: descendentes de imigrantes no sul do país; brasiguaios transeuntes na fronteira Paraná-Paraguai; pessoas surdas; indígenas em outros lugares do país. As margens, portanto, sempre estiveram presentes nessa minha trajetória, seja na escolha/adoção de cenários de pesquisa, seja nos temas de orientação de pós-graduandos. Cada um desses cenários era singular e tinha suas especificidades. $\mathrm{O}$ ponto em comum nesses cenários era o fato de serem sempre apresentados como bilíngues e minoritários e/ou minoritarizados, mas se revelarem multilíngues.

Uso a forma plural em 'multilíngues'/'multilinguismos' para remeter às diferenças existentes no que é denominado 'diversidade' linguística tanto entre línguas como dentro de uma língua. (Cf. Cavalcanti, 2006, César; Cavalcanti, 2007; Cavalcanti; Maher, 2018).

5. No original: "To be in the margin is to be part of the whole but outside the main body".

6. No original: "The promise of diversity could .... be described as a problem: the sign of inclusion makes the signs of exclusion disappear."

7. Doravante LA. 
Quanto ao conceito de 'diversidade', ele é focalizado em várias disciplinas acadêmicas, por exemplo, na Antropologia da Linguagem. Para Reyes (2014: 367), "[in]teligibilidades sobre diversidade são construídas na conceituação da diferença: cultural, étnica, linguística etc." ${ }^{8}$ Parte integrante do meu entendimento de fazer LA, a diferença é vista como discurso construído na sociedade sobre o Outro, discurso esse relacionado à subalternização e ao déficit (como'falta').

Na construção de conhecimento sobre os cenários mencionados, ou seja, sobre os discursos de diversidade, muitas vezes me deparava com a necessidade de problematização e/ou adequação de conceitos teóricos, conceitos esses, geralmente, desenvolvidos de pontos de vista distantes dos cenários investigados. Para estudar essas margens, com foco na(s) línguas em uso, no repertório comunicativo dos participantes da pesquisa, vistos em sua complexidade, no atrelamento ao social, em especial à ideologia da linguagem, as considerações sobre escolha de arcabouço teórico e sobre metodologia de pesquisa sempre foram cruciais.

No desenrolar do trabalho de pesquisa, dentro de uma perspectiva pós colonial (Santos, 2008), que enfatiza a importância da problematização teórica, o conceito de 'língua' (César; Cavalcanti, 2007) teve (e tem) papel de destaque, uma vez que está na base de conceitos derivados tais como bi- e multilinguismo. As autoras, à guisa de problematização, propuseram que o conceito cristalizado na tradição linguística como fixo e delimitador, deveria ser considerado à luz da metáfora do caleidoscópio. Nessa linha de discussão, alinho-me à solução apresentada por Makoni; Pennycook (2007) para uma mirada sociocrítica desse conceito: o desenrolar dos processos discursivos na classificação (e nomeação) das línguas, isto é, a 'desinvenção' das línguas. Continuo, porém, utilizando o termo 'língua' como construto social, parte do discurso do cotidiano, em alinhamento a Blackledge; Creese $^{9}(2014: 1)$.

8. No original: "Understandings of diversity are built on conceptualizations of difference: cultural, ethnic, linguistic, and so on."

9. Para esses dois autores, o conceito problematizado não é adequado como 'lente' para analisar práticas de linguagem. Para a análise dessas práticas, minha lente de preferência, no momento, é 'repertório comunicativo' (Rymes, 2013). (Cf. Cavalcanti; Silva, 2016.) 
Tomo ideologias de linguagem como mutáveis e contestáveis, alinhando-me a Blackledge (2005:31) quando afirma que "ideologias que parecem ser sobre língua(gem) frequentemente são sobre sistemas políticos, enquanto que ideologias que parecem ser sobre teoria política são frequente e implicitamente sobre práticas e crenças linguísticas" 10 . Podem estar na base de discussões sobre racialização e xenofobia, por exemplo (Cf. Cavalcanti; Bizon, 2017).

Em resumo, a definição dos conceitos teóricos de relevância para o trabalho de análise sempre foi decorrente do diálogo construído com os registros gerados em campo. Foram esses registros que direcionaram as leituras e as escolhas realizadas ao longo do caminho. Na seção a seguir, focalizo a etnografia como a metodologia de pesquisa que se tornou parte integrante da minha trajetória acadêmica e prossigo em direção à pesquisa de arquivo, ora em desenvolvimento.

\section{Da pesquisa etnográfica ao olhar, que não consegue deixar de ser etnográfico, sobre a 'mídia' de circulação nacional}

Minha entrada na pesquisa etnográfica ${ }^{11}$ coincidiu, conforme anunciado, com o início do trabalho no cenário indígena. Essa entrada foi pautada e ampliada pelo diálogo com os textos de Fred Erickson, então na University of Pennsylvania, e com esse pesquisador em suas várias visitas acadêmicas ${ }^{12}$ ao Brasil. Meu interesse de pesquisa já estava nessa época em questões de bi/multilinguismo e diversidade (Cf. Cavalcanti, 1999). Nesse cenário do curso de formação de professores

10. No original: “.... ideologies that appear to be about language are often about political systems, while ideologies that seem to be about political theory are often implicitly about linguistic practices and beliefs" (Blackledge, 2005:31).

11. Essa vertente da etnografia vem da Antropologia, principalmente, da Antropologia da Educação (Erickson, 1986; Erickson; Schultz, 1982), combinada à tradição da Antropologia da Linguagem estadunidense, em correntes tais como a Etnografia da Comunicação (Hymes, 1964; Gumperz; Hymes, 1972), a Sociolinguística Interacional (Gumperz, 1982), a Análise da Conversa (ou da Conversação) (Sacks, Schegloff; Jefferson, 1974). Essas correntes enfatizam o estudo da língua(gem), com foco na análise da interação, considerando aspectos sociais (Cf. Rampton, 2006). O interesse de muitos de seus pesquisadores iniciais e de seus seguidores estava em cenários multilíngues (Cf. Rampton, 2006; Martin-Jones; Martin, 2017).

12. Visitas inicialmente sugeridas e idealizadas pela pesquisadora Stella Bortoni. 
indígenas de etnias diversas, instalei a minha prática do estranhamento do familiar e da familiarização com o estranho (Erickson, 1986). Tomando essas duas práticas como complementares, a preocupação era com a(s) língua(s) em uso, em ação, em interações situadas, dentro de um contexto sociohistórico diferente e distante da perspectiva estreita do país que se narra(va) monolíngue de acordo com a ideologia do Estado-Nação. A metodologia etnográfica, propriamente dita, foi objeto de reflexão (Cf. Cavalcanti, 2006 e 2001), em especial no que se refere à pesquisa desenvolvida por professores indígenas acreanos, sob minha orientação.

Desse lugar de fazer etnografia, entrei no processo de elaboração de um novo projeto de pesquisa, desta vez, focalizando a migração recente no Brasil, um fenômeno distante do cotidiano, no hiato temporal de imigração neste país que foi formado por imigrantes/levas migratórias (Cf. Cavalcanti, 1999; Cavalcanti; Maher, 2018). Enquanto me preparava para tomar decisões sobre o projeto, o olhar etnográfico foi capturado pela observação não só da mídia impressa como também dos noticiários da TV aberta e a cabo. Em tempos de globalização atualizada na contemporaneidade, na esteira das notícias sobre a migração para a Europa e das imagens amplamente divulgadas repetidamente na TV (aberta e a cabo) de longas filas de pessoas caminhando entre fronteiras e também sendo resgatadas de barcos, muitas vezes, à deriva no mar, começaram a aparecer notícias sobre o aumento do número de pedidos de refúgio no Brasil.

No país, a migração que recebia mais atenção da 'mídia' era a haitiana ${ }^{13}$, principalmente no que se refere à maneira como as notícias eram apresentadas na TV: elas apareciam, geralmente, depois de uma entrada ao vivo sobre a migração na Europa, porém, nos dias subsequentes não eram retomadas. A meu ver parecia haver um mostraesconde dos migrantes haitianos. Essa relação da mídia televisiva com o fenômeno atiçou meu olhar para o acompanhamento das notícias em jornal impresso. Olhando retrospectivamente, houve uma imersão imediata (e quase compulsiva) em um trabalho de campo 'virtual', buscando e arquivando notícias que ficavam registradas em portais

13. Seguida pela migração síria (visto de refugiado). A migração haitiana ocorre no bojo de migração que envolve várias outras nacionalidades (Cf. Cavalcanti; Maher, 2018; Cavalcanti; Bizon, 2017). 
digitais de notícias de jornais de circulação nacional. Ao mesmo tempo continuava atenta aos noticiários televisivos como forma de empreender novas buscas nos portais de notícias. No decorrer do trabalho de observação, o que chamou muito a atenção, no caso da migração haitiana, foi o experienciar, em tempo real, a mudança acelerada dos acontecimentos.

Comecei o trabalho efetivo de garimpagem de notícias em 2013 e continuei até atravessar o ápice da migração que aconteceu em 2015. Nesse período, concomitantemente, retomei o início da migração, pósterremoto no Haiti em 2010, através de busca em arquivos digitais.

Os registros garimpados foram tomados como primários para compor o corpus de um estudo qualitativo-interpretativista ${ }^{14}$, desta vez uma pesquisa de arquivo ${ }^{15}$. Para fazer o gancho da pesquisa etnográfica com a pesquisa de arquivo, faço referência a Wortham; Reyes (2015: 143) que argumentam pela análise discursiva de eventos encadeados como sendo útil nesses dois tipos de pesquisa:

A pesquisa etnográfica coleta e analisa dados discursivos de participantes vivos de pesquisa em escalas tempo mais curtas e em escalas espaço mais limitadas. A pesquisa de arquivo coleta e analisa dados discursivos de artefatos históricos que cobrem escalas temporais e espaciais amplas. ... Dados de arquivo são geralmente incorporados à pesquisa etnográfica e vice-versa. ${ }^{16}$

No recorte do estudo para este artigo, busco desconstruir a narrativa de uma única notícia sobre o pós-ápice da migração haitiana. Essa notícia é analisada dentro de um encadeamento de eventos construído

14. Esses registros podem se tornar dados secundários (complementares) para estudo etnográfico em fase posterior da pesquisa em andamento.

15. É relevante apontar que a 'mídia' (res)surge como relevante na pesquisa contemporânea sobre globalização, linguagem e migrações transnacionais (Cf. Androutsopoulos, 2014). Ver, por exemplo, na Antropologia da Linguagem - midiatização (Jacquemet, 2005), na Sociolinguística da Globalização (Blommmaert, 2010) e na Linguística Aplicada Crítica (Pennycook, 2001).

16. No original: "Ethnographic research typically collects and analyzes discourse data from living research participants over shorter timescales and more limited spatial scales. Archival research typically collects and analyzes discourse from historical artifacts that cover broad temporal and spatial scales. ...Archival data is often incorporated into ethnographic research, and vice versa." 
com apoio de Cavalcanti; Bizon (2017), de estudos de outras áreas ${ }^{17} \mathrm{e}$ de informações existentes em fontes buscadas na internet.

Faço essa desconstrução, levando em consideração estudos de narrativas e, mais especificamente, narrativas sobre o discurso da migração. Alinho-me a Thornborrow; Coates (2005:1) no reconhecimento da centralidade do discurso narrativo "para o tecido da interação social - seja em conversas casuais, em cenários médicos e jurídicos, na família ou na escola" ${ }^{18}$ - e de sua relevância nas ciências sociais. Alinho-me ainda a Bastos; Biar (2015: 97) na adoção de "uma lente discursiva e interacional para o tratamento analítico das narrativas". A concretização dessa lente se dá com base em Wortham; Reyes (2015).

Em relação ao discurso da migração e análise discursiva, minha referência é a discussão de De Fina; Baynham (2012). Para os autores, esse tipo de análise somente passa a ser relacionada à migração, quando esta é vista como fenômeno social, em estudos que passam a ser realizados a partir do final do Século XX. Antes disso, o interesse, por exemplo, da sociolinguística era relativo a processos linguísticos (bilinguismo/multilinguismo) dos imigrantes.

\section{Contextualização da migração haitiana em uma cápsula: extrato de notícia de arquivo digital de portal de notícias}

Era promessa de futuro. Rapidamente está virando passado. Empurrados pela crise econômica, imigrantes haitianos que vieram ao país tentar reconstruir suas vidas após o terremoto de 2010 estão deixando o Brasil.

Saem pelas mesmas portas pelas quais entraram em cidades como São Paulo e Curitiba: as rodoviárias, onde chegaram aos milhares após ingressarem no país pelo Acre.

Desde o início da década, cerca de 45 mil vieram ao Brasil.

Agora, perseguem uma nova promessa de futuro - do outro lado da cor-

17. Os estudos sobre a migração contemporânea no país, fonte inestimável de dados históricos, sociológicos, numéricos e estatísticos, vêm das Ciências Sociais (Cogo; Silva, 2016; Baeninger; Peres, 2016), das Ciências da Comunicação, vertente antropológica (Campos, 2015) e da Geografia/Demografia (Oliveira, 2017). 
dilheira dos Andes, no Chile, onde o salário mínimo supera o brasileiro em cerca de US\$ 100.

Disponível em: https://www1.folha.uol.com.br/cotidiano/2016/05/1768958para-fugir-da-crise-haitianos-trocam-o-brasil-pelo-chile.shtml (Último acesso em 20.07.2018)

O extrato de notícia acima, publicado em maio de 2016 no Caderno Cotidiano/Folha de São Paulo, é aqui apresentado como uma cápsula que resume a migração haitiana no país, ilustrando a aceleração dos acontecimentos na contemporaneidade e servindo aqui como breve contextualização da notícia-foco de análise que está na próxima seção.

Na cápsula acima, a migração haitiana é colocada como uma "promessa de futuro" que não chegou a ser realizada. De fato, na linha do tempo, houve um começo tumultuado, sem planejamento e infraestrutura, principalmente, através da cidade de Brasiléia, no interior do Acre, na fronteira com a Bolívia - porta principal dessa entrada inicial.

O importante é ter em mente que a quantidade de haitianos que, em 2015, entrou no Brasil é pequena: 65.000 , sendo 33.154 inseridos no mercado formal de trabalho, de acordo com Baeninger et al. (2018:69). Leve-se aqui em consideração a dimensão continental do Brasil e seu número de habitantes (mais de 200 milhões). É relevante anotar que os números dessa migração são sempre tentativos, eles diferem entre as fontes e também entre os modos de coleta de informação (Cf. Cavalcanti; Bizon, 2017).

Antes de entrar na notícia de 2018, foco deste artigo, recupero as construções narrativas da 'mídia' sobre os migrantes haitianos, com base em manchetes de notícias no período 2013-2016 (Cf. Cavalcanti; Bizon, 2017). As manchetes foram organizadas em três fases, a saber,

- 2013 - 2015 - No caminho do crescendo do fenômeno

• 2016, semestre 1 - O ápice da migração

-2016, semestre 2 - O declínio 
Nos dados analisados (2013 - 2016), há sinais - profusão de numerais - de que a migração haitiana foi narrada pela 'mídia' como ameaça ao emprego dos nacionais. A primeira fase coincide com a entrada do país em crise política seguida de crise econômica, a taxa de desemprego em alta. A segunda fase, com o país em recessão, enfatiza o uso de números para mostrar a concretização da 'ameaça' anunciada. $\mathrm{E}$ a terceira fase utiliza os números para mostrar os migrantes saindo do país. Na construção da narrativa sobre a migração haitiana, houve ainda uma invisibilização do preconceito racializado (incluindo a xenofobia) no país. Quanto às línguas faladas pelos haitianos, foram apresentadas en passant e como línguas não prestigiadas (o creole e o francês haitiano). Nas notícias, houve mais ênfase na necessidade e urgência do ensino da língua portuguesa para os migrantes.

\section{Um recorte do corpus em análise}

Em alinhamento a Wortham; Reyes (2015: 141), mostro “... os caminhos que as formas linguísticas, os enunciados, os modelos culturais, os indivíduos e grupos percorrem através de [cadeias de] eventos" relacionadas. Na cadeia de eventos, como unidade de análise, os procedimentos incluem: (1) mapeamento dos eventos narrados; (2) identificação de potenciais "pistas indexicais" (Wortham, 2001, com base em Gumperz, 1982, e Silverstein, 1976) para construir contexto relevante, levando-se em consideração a voz dos personagens narrados no evento e também através de eventos encadeados, e (3) inferência da voz, posicionamento e ação social que as pistas podem sinalizar.

Conforme mencionado anteriormente, focalizo apenas uma notícia do final de julho de 2018, proveniente do arquivo digital do Portal de Notícias UOL/Folha de São Paulo, jornal conhecido nacionalmente e com grande circulação no país. Foi publicada no Caderno Mundo ${ }^{19}$. Da notícia (matéria assinada: Mello, 2018), copio abaixo a manchete e parafraseio o conteúdo, com algumas citações diretas do texto.

19. E não no Caderno Cotidiano onde eram publicadas as notícias sobre a migração haitiana. O Caderno Mundo, afinal, é um espaço para notícias de fora, não se constituindo, então, a notícia como uma retomada da migração? 
Observe-se que a manchete da notícia anuncia uma movimentação nova - o Brasil, mais uma vez, na rota dos haitianos depois de mudança na lei chilena. Isso é feito em um momento em que a migração haitiana já era considerada como acontecimento do passado - com os migrantes deixando/tendo deixado o Brasil rumo a outros países ${ }^{20}$, incluindo o Chile:

Após mudança de lei no Chile, haitianos voltam a procurar o Brasil Entrada no país ganha força depois de governo Sebastián Piñera endurecer legislação sobre imigração

Disponível em: https://www1.folha.uol.com.br/mundo/2018/07/apos-mudanca-de-lei-no-chile-haitianos-voltam-a-procurar-o-brasil.shtml. (Último acesso 30/07/2018)

No enunciado da manchete, através de escolhas lexicais e tempo verbal, há um jogo entre o presente e o passado recente: 'mudança' legislação chilena. O verbo 'voltar' está no tempo presente em uma expressão verbal que remete ao passado ("voltam a procurar o Brasil"). Em outras palavras, para quem acompanhou a migração haitiana, a manchete é um fato novo, que levanta a possibilidade de a migração ser retomada. Ela lança um olhar em retrospectiva e faz projeções para o futuro próximo. O subtítulo da manchete, elabora a informação, colocando ênfase no aumento da entrada de migrantes no país com o uso da expressão verbal "ganha força" combinada à escolha lexical "endurecer" para descrever a mudança na legislação chilena.

O impacto potencial anunciado na manchete da notícia é concretizado já na primeira linha do texto: "nova onda", "migrantes haitianos", "chegando ao Brasil". O tempo verbal continua a ser o tempo presente, mas um presente em movimento real de chegada/entrada. Em seguida aparece o número - "300", a indicação temporal - "nas últimas semanas", - o local de entrada - "Corumbá (Mato Grosso do Sul), na fronteira com a Bolívia" e uma foto com pouco mais de 6 migrantes em um salão grande e vazio com a legenda contendo a expressão "abrigo improvisado".

A seguir o texto passa à utilização de numerais em sequência ("em média 15 novos haitianos todo dia na cidade"; "Em 2018, até 22 de 
junho, foram 643" - o que representa um aumento de "10.000\%"). Esses números corroboram a ideia do aumento da migração haitiana e podem potencializar o desconforto social daqueles que vêem a migração como 'ameaça' de competição em tempos de taxa alta de desemprego no país. Anote-se que esse tipo de ameaça já era parte integrante das notícias no período de 2011 a 2015, quando a 'mídia' de circulação nacional batia na tecla do aumento exponencial de migrantes lado a lado com as notícias sobre o aumento da taxa de desemprego no país (Cf. Cogo; Silva, 2016; Cavalcanti; Bizon, 2017).

Na notícia em análise, com base em outros números, além daqueles dos migrantes que estão chegando, um crescendo continua a ser construído, desta vez com o foco no aumento da solicitação de visto de refugiado no país: "O número de haitianos pedindo refúgio no Brasil


até 22 de junho, alta proporcional de $84 \%$ ”. Chama atenção a escolha lexical do verbo 'explodir' para dimensionar o aumento exponencial, mesmo havendo a explicitação de que se trata de "alta proporcional". É essa alta súbita/inesperada - indicializada pelo verbo 'explodir' no passado - que marca a volta da 'ameaça' estrangeira, com foco nos haitianos. E como se fosse para acrescentar a gota d'água que pode fazer transbordar esse aumento de solicitação de refúgio, há, ainda, na notícia, a indicialização de expansão demográfica com a utilização de citação: "Temos várias grávidas chegando, algumas no oitavo, nono mês de gestação". Note-se que não é apenas uma mulher grávida, são 'várias', e algumas prestes a dar à luz. A voz acionada na notícia é do padre Ribeiro da "Pastoral da Mobilidade Urbana em Corumbá".

Depois deste crescendo, o texto volta para o que prenuncia a manchete: a causa da vinda (ou seria um anúncio da volta?) dos haitianos para o Brasil devido ao fechamento das leis do Chile para imigração. Há uma explicação sobre as mudanças legislativas depois que Sebastian Piñera, o novo presidente da república chilena, "tomou posse em março" de 2018. Uma dessas mudanças se refere a "vistos humanitários [a partir dessa data emitidos] exclusivamente na embaixada em Porto Príncipe".

Das leis de imigração no Chile, a notícia passa a focalizar as mudanças nas leis de imigração no Brasil: a concessão de vistos huma- 
nitários aqui assim como no Chile, está agora restrita à embaixada do Brasil no Haiti, ou seja, o visto não é mais disponível para haitianos chegando ao Brasil de outros lugares.

De acordo com a notícia: "A maioria dos haitianos que chega a Corumbá recebe notificação de saída da Polícia Federal, que dá a eles prazo de 60 dias para se regularizarem ou então ficarem sujeitos a deportação." Note-se que esta informação surge depois de não ter havido resposta da PF sobre informações solicitadas: "Procurada, a Polícia Federal afirmou que não tem dados consolidados sobre as notificações de saída". Vê-se aqui uma indicialização avaliativa implícita da PF que poderia ser traduzida em uma pergunta: como pode a instituição não ter uma resposta para a solicitação?

A voz do padre é ainda acionada (a) em discurso direto, posicionando os migrantes com olhar humanizado, referenciando-os e predicandoos como vítimas de coiotes extorquidores ("Chegam muito fragilizados e sem nenhum dinheiro") e (b) em discurso indireto, informando sobre a viagem deles do Chile para o Brasil via Bolívia.

Segundo o padre Ribeiro, os haitianos saem do Chile, pagam coiotes para atravessar de van a Bolívia e chegar até Puerto Quijarro, ao lado de Corumbá. Muitos têm familiares no Brasil. 'Chegam muito fragilizados e sem nenhum dinheiro, porque são extorquidos no caminho', diz Ribeiro.

A notícia é finalizada com a mobilização de outra voz, a do coordenador da Defensoria Pública da União em São Paulo. Nessa citação, o discurso direto é usado para reafirmar de modo enfático (e sem apoio de números) a ocorrência da retomada da migração. Na citação, "cada vez mais gente" vai chegar e há o "risco" de Corumbá vir a ser uma "nova" porta de entrada (em comparação a Brasiléia e Pacaraima). Tem-se, então, mais uma vez, o apoio de voz, supostamente, com credibilidade, mobilizada para fechar, de modo dramático, a notícia sobre a (re)entrada de haitianos no país:

Chaves defende que o visto humanitário para haitianos seja concedido em qualquer embaixada brasileira. "Vai chegar cada vez mais gente. Há o risco de Corumbá se transformar na nova Brasileia [no Acre, onde se concentraram milhares de haitianos no começo da década] ou Pacaraima [em Roraima, por onde entram os venezuelanos]", afirma o coordenador. 
No trecho acima, nota-se, ainda, o recurso da inserção da voz do jornalista, entre colchetes na citação do coordenador, indicando a localização das cidades: (a) para fazer lembrar o início da migração haitiana e (b) para marcar os migrantes 'da vez' na 'mídia' - venezuelanos.

No texto da notícia, os haitianos, posicionados como um coletivo homogêneo, são narrados com o apoio dessas duas vozes, apresentadas como de credibilidade. Talvez haja uma pressuposição de que elas sejam conhecidas pelo público leitor. No entanto, um padre de pastoral regional e um coordenador da DPU, lotado em São Paulo, não, necessariamente, são figuras conhecidas nacionalmente. Qual seria a importância dessas pessoas e o que podem significar essas escolhas?

Em relação ao padre, pelo texto da notícia, sabe-se que ele é "responsável pela Pastoral da Mobilidade Humana" e "coordenador do Comitê Estadual de Enfrentamento de Tráfico de Pessoas em Mato Grosso do Sul". Como a causa migrante tem sido apoiada e acolhida por projetos e organizações não-governamentais religiosas ${ }^{21}$ (católicas e evangélicas) e também laicas (Cf. Cogo; Silva, 2016), uma busca digital se fazia necessária. Na busca realizada, encontrei, no portal do Jornal Midiamax de Corumbá/MS, uma notícia assinada, por Cavalcante (2018), que focaliza a liderança de Ribeiro na cidade. O padre também preside um comitê humanitário criado em julho/18 e formado por voluntários "da sociedade civil" que inclui "entidades religiosas": "Comitê Humanitário Pantanal Solidário (CHPAS)". A notícia de Cavalcante explicita que os objetivos desse comitê incluem "organizar" e "distribuir as ações de acolhimento a haitianos". Vejo esses objetivos como buscando preencher a lacuna do Estado na coordenação do atendimento aos migrantes.

No que se refere ao coordenador de migrações e refúgios da DPU, a notícia analisada é econômica em informações, mas, de novo, via busca digital, seu nome surgiu em uma lista de links tanto para matérias em jornais impressos nacionais como também para o site da Defensoria Pública da União e, ainda, para o site do Conselho Indigenista

21. Ver, por exemplo, o trabalho da Missão Paz na cidade de São Paulo e da Cáritas na cidade do Rio de Janeiro, ambas ligadas à Igreja Católica. Cogo; Silva (2016) também mencionam o trabalho de missionários evangélicos e entidades da sociedade civil. 
Missionário (CIMI ${ }^{22}$. Escolhi priorizar os dois sites, uma vez que traziam informações mais detalhadas, e deixar os jornais como pano de fundo.

No site da Defensoria Pública da União (DPU, 2018) há uma informação sobre a relação de Chaves com a migração haitiana via Corumbá. Como defensor público federal, em junho de 2018, ele fez parte do Projeto ${ }^{23}$ Corumbá,

uma ação que levou assistência e orientação jurídica aos migrantes em situação de vulnerabilidade. A atividade ocorreu no âmbito da Ação Global Contra o Tráfico de Pessoas e Contrabando de Migrantes (GLO.ACT), e foi desenvolvida em parceria com a Organização das Nações Unidas (ONU) e entidades da sociedade civil. (DPU, 2018)

Além da participação no Projeto Corumbá, desta vez no âmbito da migração venezuelana, os links de jornais, na busca realizada, fazem referência a Chaves como tendo feito parte de uma missão ${ }^{24}$ do Conselho Nacional de Direitos Humanos, em janeiro de 2018. No site do Conselho Indigenista Missionário, há um detalhamento dessa missão que teve como objetivo "verificar a situação dos direitos humanos de imigrantes venezuelanas e venezuelanos" (CIMI, 2018). A missão visitou Belém e Santarém/Pará, Manaus/Amazonas e Boa Vista e Pacaraima/Roraima e elaborou um documento que contém uma

Recomendação conjunta à Presidência da República, Casa Civil, Governo do Estado de Roraima e Prefeitura do Município de Boa Vista, demandando urgência no início da gestão por parte do poder público do abrigo do ginásio Tancredo Neves, na cidade de Boa Vista, no sentido que este ofereça as condições adequadas de abrigamento e garantia dos direitos humanos (CIMI, 2018).

22. O CIMI, em seu site: cimi.org.br, se apresenta como vinculado à CNBB (Conferência Nacional dos Bispos do Brasil).

23. O Projeto teve como desdobramento a convocação de uma audiência pública pelo Ministério Publico Federal para agosto de 2018 em Corumbá (Cf. DPU, 2018).

24. A missão, com acompanhamento da Organização Internacional para as Migrações no Brasil, foi integrada por representantes do Ministério Público Federal (MPF), da Conectas Direitos Humanos, da Defensoria Pública da União (DPU) e da Missão Paz. (Cf. CIMI, 2018). 
É relevante acrescentar ainda que a missão, segundo o CIMI, detectou vários problemas, entre eles:

... a falta de coordenação de ações nos três níveis de governo e o baixo compartilhamento de informações sobre o fluxo migratório que resultam muitas vezes em inadequadas respostas do poder público à acolhida das venezuelanas e dos venezuelanos que estejam em consonância com o respeito aos direitos humanos (CIMI, 2018).

O coordenador Chaves, na notícia em análise, portanto, tem um peso forte de credibilidade no assunto migração: como representante da União, ele fez parte da missão do CNDH relativa aos migrantes venezuelanos, ou seja, está inserido no assunto da migração contemporânea no Brasil (com diálogo internacional) tanto pelo cargo que ocupa como também pelas ações práticas decorrentes desse cargo. Além disso, o que é especialmente relevante para este artigo, participou do Projeto Corumbá, com foco específico nos migrantes haitianos que estão entrando por essa fronteira do Brasil com a Bolívia, vindos do Chile.

Sobre a escolha dessas duas vozes para compor a notícia, por um lado, pode-se levantar a hipótese de que elas são importantes para mostrar um viés mais humanizado em relação aos migrantes através de ações sociais mais concretas e pontuais do que o que é, geralmente, apresentado pelo Estado. Por outro lado, o trazer essas citações do representante não-governamental/religioso e também do braço governamental que está ligado ao $\mathrm{CNDH}$, pode ser visto como uma estratégia de fortalecimento do discurso da 'mídia', que, geralmente, está calibrada com as ideologias das políticas públicas neoliberais no que se refere à migração (Cf. De Fina; Baynham, 2012).

\section{Algumas considerações transitórias}

O ir e vir é parte integrante de uma onda migratória: há os que ficam, os que mudam de lugar no país (em função de oferta/possibilidade de trabalho ou de políticas governamentais de interiorização), os que saem do país e não voltam, os que saem e voltam, os que chegam pela primeira vez. O trânsito de migrantes, portanto, é continuado tanto dentro do país hospedeiro como fora dele. Não se pode deixar de anotar 
que, nesse trânsito hoje dependente da tecnologia (acesso a internet e celular), esses cenários de migração são mais mutantes e mais acelerados. E, apesar dos avanços (ainda bem caros!) na comunicação e na mobilidade, são muitos os relatos de viagens demoradas, muitas vezes nas mãos de coiotes/extorquidores, com esperas nas faixas fronteiriças, que podem incluir também longas caminhadas a pé.

Tendo acompanhado a migração haitiana desde seu início, passando pelo seu ápice (2015) e presenciado seu declínio (2016), não houve, portanto, surpresa com a informação focalizada na notícia-foco de análise neste artigo: uma retomada da onda migratória. $\mathrm{O}$ que deve ser salientado aqui é que nessa notícia, assim como nos dados do período 2013-2016, os "números pequenos" (Appadurai, 2006) dessa migração são apresentados pela 'mídia' como incomuns, ou de acordo com Rampton (2006: 117) são apresentados como "espetaculares" e, como tal, merecedores de atenção e divulgação. E como parte dessa espetacularização, a estatística apresentada com base nesses números pequenos é grande (p.ex., "um aumento de 10.000\%", "84\%"), e, nem sempre, se deixa muito claro qual é o ponto de comparação. Recria-se, assim,para o leitor a ideia de impacto social e econômico perigoso: volta a narrativa da migração haitiana como uma 'ameaça' para a população do país - ainda em recessão - e para seu mercado de trabalho com taxa de desemprego alta ${ }^{25}$. Acresça-se a isso que a retomada dessa narrativa sobre a migração haitiana se dá em meio à onda migratória venezuelana (também com números pequenos!26), ora muito presente no noticiário televisivo (com foco na precariedade do acolhimento e em episódios de xenofobia).

A narrativa construída na notícia analisada mobiliza vozes representativas do acolhimento aos migrantes. Uma dessa vozes, aponta problemas nas políticas públicas e busca solucioná-los com apoio da sociedade civil. A outra voz é representante do ministério público e está ligada ao atendimento governamental aos migrantes. Vejo, no entanto, esse vozeamento como uma estratégia para potencializar o valor

25. Mais de $12 \%$, cerca de 13 milhões de desempregados, conforme continuamente informado em noticiários televisivos.

26. Estima-se que 128 mil entraram nos últimos 18 meses via Pacaraima. Na Colômbia, por exemplo, vivem cerca de 1 milhão de venezuelanos (https://oglobo.globo.com/mundo/ raio-da-emigracao-entenda-exodo-de-venezuelanos-para-paises-vizinhos-22430364). 
da narrativa construída para posicionar a migração como ameaça ao mercado de trabalho no país, com taxa de desemprego alta, em tempo de crise econômica. Ou seja, a estratégia parece estar calibrada com as ideologias das políticas governamentais neoliberais. Para quem é a favor da migração, a estratégia causa desconforto social. Para aqueles que são contra, ela pode encorajar a ampliação de comentários raivosos, já presentes no dia-a-dia e nas redes sociais dos tempos atuais.

Na notícia analisada neste artigo, há uma retomada/repetição das estratégias utilizadas na narrativa de 'ameaça' construída pela 'mídia' entre 2013-2015, ou seja, mais uma vez, o foco é colocado nos números (pequenos) e, na estatística apresentada, muitas vezes, não há ponto de comparação explicitado. Para Jaworski (2007: 346), a 'mídia' tem capacidade de alcance e influência e consegue "pinçar certos fatos, mesmo que pequenos, e transformá-los em histórias, pânico moral e debates, especialmente se o fato é suficientemente negativo para aumentar o valor da notícia ${ }^{27}$."

Para finalizar, justifico a transitoriedade das considerações neste artigo não somente porque o mundo contemporâneo é caracterizado pela aceleração, pela mobilidade e pelos avanços da tecnologia, mas também porque, na trajetória de pesquisa pela qual enveredei, as escolhas epistemológicas foram pensadas não somente para contemplar desafios na construção de inteligibilidades sobre cenários vistos como marginais na academia/sociedade, mas para serem passíveis de problematização. Quanto aos desafios, eles sempre incluíram o levantamento de implicações sociais; na pesquisa, ora em andamento, as implicações servirão para repensar, por exemplo, a formação de profissionais da educação para esse futuro-presente, cada vez mais complexo e cada vez mais mutante na paisagem espaço temporal e linguístico-comunicativa do país.

27. No original: “... to 'pick up' certain issues, however small, and turn them into stories, moral panics and debates, especially if the issue is sufficiently negative to increase its news values." 


\section{Referências}

AHMED, Sara. 2012. On being included - Racism and diversity in institutional life. Durham and London: Duke University Press.

ANDROUTSOPOULOS, Janis. 2014. Mediatization and sociolinguistic change. Key concepts, research traditions, open issues. In: Janis Androutsopoulos (ed.). Mediatization and Sociolinguistic Change. Berlin: De Gruyter, p. 3-48.

APPADURAI, Arjun. 2006. Fear of Small Numbers - An essay on the geography of anger. London: Duke University Press.

BAENINGER, Rosana; PERES, Roberta. 2016. Imigração Haitiana em São Paulo: perfil e ocupação. In: Roberta Baeninger et al. (orgs.). Imigração Haitiana no Brasil. Jundiaí: Paco Editorial, p. 253-266.

BAENINGER, Rosana et al. (orgs.). 2018. Migrações Sul-Sul. Campinas, SP: Núcleo de Estudos de População Elza Berquó - Nepo/Unicamp.

BASTOS, Liliana C.; BIAR, Liana de A. 2015. Análise de narrativa e práticas de entendimento da vida social. D.E.L.T.A.31/Especial, p. 97-126.

BLACKLEDGE, Adrian. 2005. Discourse and Power in a Multilingual World. Amsterdam: John Benjamins.

; Angela Creese. 2014. Heteroglossia as practice and theory. In: Adrian Blackledge; Angela Creese (eds.). Heteroglossia as practice and theory. Dordrecht/Nova York/Heidelberg: Springer, p. 1-20.

BLOMMAERT, Jan. 2010. The Sociolinguistics of Globalization. Cambridge: Cambridge University Press.

CAMPOS, Gustavo B. de. 2015. Dois Séculos de Imigração no Brasil - A construção da imagem e papel social dos estrangeiros pela imprensa entre 1808 e 2015. Tese de doutorado. Universidade Federal do Rio de Janeiro.

CAVALCANTE, Guilherme. 2018. Posto de imigração da PF volta a intensifcar notificações de haitianos em Corumbá. Jornal Midiamax. Corumbá/MS:18/07/2018 12h23. Disponível em: https://www. midiamax.com.br/cotidiano/2018/posto-de-imigracao-da-pf-voltaa-intensificar-notificacoes-de-haitianos-em-corumba/

CAVALCANTI, Marilda C. 1999. Estudos sobre educação bilíngue e escolarização em contextos de minorias linguísticas no Brasil. D.E.L.T.A.15/Especial, p. 385-417.

2001. A pesquisa do professor como parte da educação continuada em curso de magistério indígena no Acre. In: Angela B. Kleiman (org.). A formação do professor: perspectivas da linguística aplicada. Campinas: Mercado de Letras, p. 219-238. 
2006. Um olhar metateórico e metametodológico em linguística aplicada - implicações éticas e políticas. In: Luiz P. Moita-Lopes (org.). Por uma Linguística Aplicada Indisciplinar. São Paulo: Parábola, p. 233-252.

; SILVA, Ivani R. 2016. Transidiomatic practices in a deaf-hearing scenario and language ideologies. Revista da Anpoll 40/Dossiê: 3345. Disponível em: https://revistadaanpoll.emnuvens.com.br/revista/ issue/view/42/showToc

; MAHER, Terezinha M. 2018. Contemporary Brazilian perspectives on multilingualism - An Introduction. In: Marilda, C. Cavalcanti; Terezinha M. Maher (eds.). Multilingual Brazil:Language resources, ideologies and identities in a globalized world. New York: Routledge, p. 1-17.

; BIZON, Ana Cecília C. 2017. Migrantes no(s) desfocos da mídia no Brasil. Comunicação apresentada no Simpósio Bordas e Fronteiras do Português Globalizado. VI SIMELP (Simpósio Mundial de Estudos da Língua Portuguesa). Santarém, Portugal: 24 - 28 de agosto.

CÉSAR, América L.; CAVALCANTI, Marilda C. 2007. Do singular para o multifacetado: o conceito de língua como caleidoscópio. In: Marilda, C. Cavalcanti; Stella M. Bortoni-Ricardo (orgs.). Transculturalidade, Linguagem e Educação. Campinas: Mercado de Letras, p. 45-66.

CIMI. 2018. CNDH aprova recomendação emergencial sobre direitos de imigrantes venezuelanos no Brasil. Publicado 02/02/18 no site do Conselho Indigenista Missionário: cimi.org.br em 02/02/18. Disponível em: https://cimi.org.br/2018/02/cndh-aprova-recomendacaoemergencial-sobre-direitos-de-imigrantes-venezuelanos-no-brasil/

COGO, Denise; SILVA, Terezinha. 2016. Entre a fuga e a invasão: alteridade e cidadania da imigração haitiana na mídia brasileira. Revista FAMECOS (online) - mídia, cultura e tecnologia, 23/1 - páginas não indicadas. DOI: http://dx.doi.org/10.15448/19803729.2016.1.21885 - Disponível em: http://revistaseletronicas.pucrs. br/ojs/index.php/revistafamecos/article/view/21885/13676 (Último acesso em 12/10/2017).

DE FINA, Anna; BAYNHAM, Mike. 2012. Immigrant discourse. The Encyclopedia of Applied Linguistics. London: Wiley Blackwell.

DPU. 2018. DPU participa de audiência pública sobre imigração haitiana em Corumbá. Publicado no site: dpu.jusbrasil.com.brem26/08/18. Disponível em: https://dpu.jusbrasil.com.br/noticias/603078038/ dpu-participa-de-audiencia-publica-sobre-imigracao-haitiana-emcorumba 
ERICKSON, Frederick. 1986. Qualitative methods in research on teaching. In: Merlin C. Wittrock (ed.). Handbook of Research on Teaching. New York: MacMillan.

; SCHULTZ, Jeffrey. 1982. The Counselor as Gatekeeper-Social Interaction in Interviews. New York: Academic Press.

GUMPERZ, John. 1982. Discourse Strategies. Cambridge: Cambridge University Press.

; HYMES, Dell (eds.). 1972. Directions in Sociolinguistics: The Ethnography of Communication. Oxford: Blackwell.

HOOKS, bell. 1984. The Feminist Theory: from margin to center. Boston: South End Press.

HYMES, Dell. 1964. Introduction: Toward ethnographies of communication. American Anthropologist, 66(6), p. 1-34.

JACQUEMET, Marco. 2005. Transidiomatic practices: Language and power in the age of globalization. Language \& Communication 25, p. 257-277.

JAWORSKI, Adam. 2007. Language in the media. In: Sally Johnson; Astrid Ensslin (eds.). Language in the Media - representations, identities, ideologies. London: Continuum, p. 345-356.

MAKONI, Sinfrey; PENNYCOOK, Alasdair (eds.). 2007. Disinventing and Reconstituting Languages. Clevedon: Multilingual Matters.

MARTIN-JONES, Marilyn; MARTIN, Deirdre. 2017. Introduction. In: Marilyn Martin-Jones; Deirdre Martin (eds.). Researching Multilingualism - Critical and ethnographic perspectives. New York: Routledge, p. 1-27.

MELLO, Patrícia C. 2018. Após mudança de lei no Chile, haitianos voltam a procurar o Brasil. Publicado no site: folha.uol.com.br em 01/7/18 02h00. Disponível em: https://www1.folha.uol.com.br/ mundo/2018/07/apos-mudanca-de-lei-no-chile-haitianos-voltam-aprocurar-o-brasil.shtml. Acesso em: 30/07/2018.

OLIVEIRA, Wagner. 2017. Haitianos no Brasil: Hipóteses sobre a distribuição espacial dos imigrantes pelo território brasileiro. FGV - DAPP. Disponível em: http://dapp.fgv.br/haitianos-no-brasilhipoteses-sobre-distribuicao-espacial-dos-imigrantes-pelo-territoriobrasileiro/. Publicado em 2017. Acesso em: 30/04/2018.

PENNYCOOK, Alasdair. 2001. Critical Applied Linguistics: A critical introduction. Mahwah, NJ and London: Erlbaum.

PIETKAINEN, Sari; KELLY-HOLMES, Helen. 2013. Multilingualism and the periphery. In: Sari Pietkainen; Helen Kelly-Holmes (eds.). Multilingualism and the Periphery. New York: Oxford, p. 1-16. 
RAMPTON, Ben. 2006. Continuidade e mudança nas visões de sociedade em linguística aplicada. In: Luiz P. Moita-Lopes (org.). Por uma Linguística Aplicada Indisciplinar. São Paulo: Parábola, p. 109-128.

REYES, Angela. 2014. Linguistic Anthropology in 2013: Super-New-Big. American Anthropologist, 116/2, p. 366-378.

RYMES, Betsy. 2013. Communicating beyond language - Everyday encounters with diversity. New York/London: Routledge.

SACKS, Harvey, Emanuel Schegloff; Gail Jefferson. 1974. A simplest systematics for the organisation of turn-taking in conversation. Language 50, p. 696-735.

SANTOS, Boaventura S. 2008. Do pós-moderno ao pós-colonial. E para além de um e de outro. Travessias 6/7, p. 15-36.

SILVERSTEIN, Michael. 1976. Shifters, linguistic categories, and cultural description. In: Henry Selby; Keith Basso (eds.). Meaning in Anthropology. Albuquerque: University of New Mexico Press, p. 11-55.

THORNBORROW, Joanna; Jennifer Coates. 2005. The sociolinguistics of narrative - identity, performance and culture. In: Joanna Thornborrow; Jennifer Coates (eds.). The Sociolinguistics of Narrative. Amsterdam/ Philadelphia: John Benjamins, p. 1-16.

WORTHAM, Stanton. 2001. Narratives in Action. New York: Teachers College.

WORTHAM, Stanton; Angela Reyes. 2015. Discourse Analysis beyond the Speech Event. New York: Routledge.

Recebido em: 20/09/2018

Aprovado em: 31/10/2018 